Louisiana State University

LSU Digital Commons

8-23-2016

\title{
Crystal Structure of Carboxyltransferase from Staphylococcus aureus Bound to the Antibacterial Agent Moiramide B
}

\author{
Molly A. Silvers \\ Louisiana State University \\ Svetlana Pakhomova \\ Louisiana State University \\ David B. Neau \\ Cornell University \\ William C. Silvers \\ UT Southwestern Medical School \\ Nicholas Anzalone \\ Louisiana State University
}

See next page for additional authors

Follow this and additional works at: https://digitalcommons.Isu.edu/biosci_pubs

\section{Recommended Citation}

Silvers, M., Pakhomova, S., Neau, D., Silvers, W., Anzalone, N., Taylor, C., \& Waldrop, G. (2016). Crystal Structure of Carboxyltransferase from Staphylococcus aureus Bound to the Antibacterial Agent Moiramide B. Biochemistry, 55 (33), 4666-4674. https://doi.org/10.1021/acs.biochem.6b00641 


\section{Authors}

Molly A. Silvers, Svetlana Pakhomova, David B. Neau, William C. Silvers, Nicholas Anzalone, Carol M. Taylor, and Grover L. Waldrop 


\title{
Crystal Structure of Carboxyltransferase from Staphylococcus aureus Bound to the Antibacterial Agent Moiramide B
}

\author{
Molly A. Silvers ${ }^{\dagger}$, Svetlana Pakhomova ${ }^{\dagger}$, David B. Neau ${ }^{\S}, \|$, William C. Silvers ${ }^{\perp}$, Nicholas \\ Anzalone $^{\dagger}$, Carol M. Taylor ${ }^{\ddagger}$, and Grover L. Waldrop ${ }^{*}{ }^{\dagger}$ \\ †Division of Biochemistry and Molecular Biology, Louisiana State University, Baton Rouge, \\ Louisiana 70803, United States \\ ‡Department of Chemistry, Louisiana State University, Baton Rouge, Louisiana 70803, United \\ States \\ §Department of Chemistry and Chemical Biology, Cornell University, Ithaca, New York \\ 14853-1301, United States \\ "Northeastern Collaborative Access Team, Argonne National Laboratory, Argonne, Illinois 60439, \\ United States \\ ${ }^{\perp}$ Department of Radiology, University of Texas Southwestern Medical Center, Dallas, Texas \\ 75390, United States
}

\begin{abstract}
The dramatic increase in the prevalence of antibiotic-resistant bacteria has necessitated a search for new antibacterial agents against novel targets. Moiramide B is a natural product, broadspectrum antibiotic that inhibits the carboxyltransferase component of acetyl-CoA carboxylase, which catalyzes the first committed step in fatty acid synthesis. Herein, we report the $2.6 \AA$ resolution crystal structure of moiramide B bound to carboxyltransferase. An unanticipated but significant finding was that moiramide B bound as the enol/enolate. Crystallographic studies demonstrate that the (4S)-methyl succinimide moiety interacts with the oxyanion holes of the enzyme, supporting the notion that an anionic enolate is the active form of the antibacterial agent. Structure-activity studies demonstrate that the unsaturated fatty acid tail of moiramide B is needed only for entry into the bacterial cell. These results will allow the design of new antibacterial agents against the bacterial form of carboxyltransferase.
\end{abstract}

\section{Graphical abstract}

\footnotetext{
“Corresponding Author: Address: 509 Choppin Hall, Louisiana State University, Baton Rouge, LA 70803. gwaldro@1su.edu. Supporting Information

The Supporting Information is available free of charge on the ACS Publications website at DOI: 10.1021/acs.biochem.6b00641.

${ }^{1} \mathrm{H}$ and ${ }^{13} \mathrm{C}$ NMR spectra for compounds and supplemental figures and tables (PDF)

Accession Codes

The atomic coordinates and structure factors for the moiramide B-S. aureus carboxyltransferase complex have been deposited in the Protein Data Bank as entry 5KDR.

Notes

The authors declare no competing financial interest.
} 


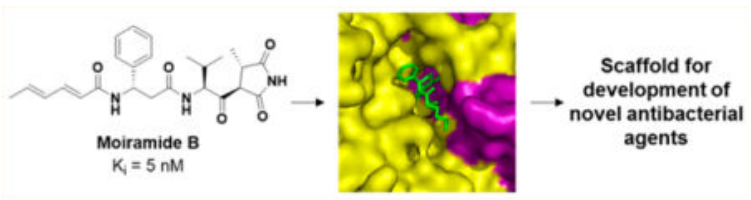

As the frequency of antibiotic-resistant infections steadily increases, there is an urgent need for new antibacterial agents. ${ }^{1}$ Natural products or derivatives thereof constitute most of the antibiotics that are in current use clinically. Natural product antibiotics inhibit only four metabolic processes: DNA replication, transcription/translation, folate metabolism, and cell wall biosynthesis. ${ }^{2}$ A critical pathway in assembly of the bacterial cell wall is fatty acid synthesis. Thus, key enzymes in fatty acid biosynthesis can be considered targets for antibacterial development. ${ }^{3-5}$ There are only four natural product antibiotics that inhibit enzymes in fatty acid biosynthesis. ${ }^{1}$ One of those is moiramide B [compound $\mathbf{1}$ (Figure 1A)], which inhibits acetyl-CoA carboxylase and is the subject of this report.

The first committed and regulated step in fatty acid synthesis is catalyzed by acetyl-CoA carboxylase (ACC). ${ }^{6}$ In most Gram-positive and Gram-negative bacteria, the enzyme consists of three discrete proteins: biotin carboxylase, biotin carboxyl carrier protein, and carboxyltransferase. ${ }^{7}$ These three proteins form a complex in $v i v O^{8}$ and catalyze the two-step reaction shown in Scheme 1. Biotin carboxylase (BC) catalyzes the first half-reaction in Scheme 1, which involves the ATP-dependent phosphorylation of bicarbonate to form a reactive carboxyphosphate intermediate. ${ }^{9}$ The carboxyl group is then transferred to the vitamin biotin, which in vivo, is covalently attached to the biotin carboxyl carrier protein (BCCP). The second half-reaction is catalyzed by the carboxyltransferase (CT) component, which transfers the carboxyl group from carboxybiotin to acetyl-CoA to make malonyl$\mathrm{CoA}$. When $\mathrm{BC}$ and $\mathrm{CT}$ are purified, they retain their activity, processing free biotin rather than biotin attached to BCCP. ${ }^{10}$

Both the biotin carboxylase and the carboxyltransferase components of acetyl-CoA carboxylase have been validated as targets for antibacterial agents. Three different synthetic scaffolds have been reported to inhibit $\mathrm{BC}$ and exhibit antibacterial activity: pyridopyrimidines, ${ }^{11}$ aminooxazoles, ${ }^{12}$ and benzimidazole-carboxamides. ${ }^{13}$ In contrast, there is currently only one class of molecules known to inhibit CT, the natural products moiramide B and andrimid. Moiramide B [compound 1 (Figure 1A)] is a pseudopeptide that was extracted from a marine isolate of Pseudomonas fluorescens and was found to have broad-spectrum antibacterial activity. ${ }^{14}$ Ten years after the discovery of the antibiotic properties of moiramide B, Freiberg et al. determined that CT was the cellular target. ${ }^{15}$ However, the mechanistic basis for moiramide B inhibition of CT was unclear.

Herein, we report the three-dimensional structure of moiramide B bound to carboxyltransferase. An interesting and important finding is that the enzyme binds the enol/ enolate of moiramide B (Figure 1B). Structure-activity studies of moiramide B are also described, which dissect moiramide B into fragments, and the functions of those fragments are determined with respect to the inhibition of CT and also the viability of Escherichia coli. Comparison of the results is instructive vis-à-vis the roles of the various functionalities in 
moiramide B. The combined structure-function approach illustrates how nature has evolved a tight binding inhibitor $\left(K_{\mathrm{i}}=5 \mathrm{nM}\right)$ of $\mathrm{CT}$ with antibacterial activity, ${ }^{15}$ invoking many principles of medicinal chemistry. Our findings explain the molecular interactions between a lead compound, moiramide B, and the enzyme active site, laying the foundation for future design of antibacterial agents.

\section{EXPERIMENTAL PROCEDURES}

All chemicals and reagents were purchased from Sigma-Aldrich, Fisher, Acros, NovaBiochem, and Fluka and used without further purification. Diisopropylethylamine and triethylamine were dried and distilled from $\mathrm{CaH}_{2}$ and stored over $\mathrm{KOH}$ pellets. Dry methanol was distilled from Mg turnings and stored over $3 \AA$ molecular sieves. All reactions were performed under a dry nitrogen atmosphere unless otherwise noted. Flash chromatography was performed using 230-400 mesh silica gel (40-63 $\mu \mathrm{m})$ from Fluka. Thin layer chromatography was performed on aluminum-backed $60 \mathrm{~F}_{254}$ silica plates from EMD Chemicals, Inc. Optical rotations were recorded on a Jasco P-2000 digital polarimeter. ${ }^{1} \mathrm{H}$ and ${ }^{13} \mathrm{C}$ NMR spectra were recorded at room temperature on a Bruker AV-400 spectrometer. All NMR experiments were performed in deuterated solvents, and the chemical shifts are reported in standard $\delta$ notation as parts per million, using tetramethylsilane (TMS) and $\mathrm{CDCl}_{3}$ as internal standards with coupling constants $(J)$ reported in hertz. High-resolution mass spectrometry (HRMS) was conducted using an Agilent 6210 electrospray ionization time-of-flight (ESI-TOF) mass spectrometer.

\section{(3S)-Methyl-pyrrolidine-2,5-dione (2)}

A catalytic amount of 5\% Pd/C [100 mg, 20\% (w/w)] was added to a solution of (4S)methyl- $N$ - $O$-benzyl-pyrrolidine-2,5-dione ${ }^{16}(500 \mathrm{mg}, 2.28 \mathrm{mmol}, 1.00$ equiv) in dry methanol $(25 \mathrm{~mL})$ and the mixture stirred under $\mathrm{H}_{2}$ for $1 \mathrm{~h}$. The reaction mixture was filtered through a pad of Celite, washed with methanol, and concentrated. The residue was dissolved in acetonitrile $(5 \mathrm{~mL})$ and added dropwise to a stirred solution of 2bromoacetophenone ( $454 \mathrm{mg}, 2.28 \mathrm{mmol}, 1.00$ equiv) in acetonitrile $(5 \mathrm{~mL})$ at room temperature. A solution of triethylamine ( $477 \mu \mathrm{L}, 346 \mathrm{mg}, 3.42 \mathrm{mmol}, 1.50$ equiv) in acetonitrile $(2 \mathrm{~mL})$ was added dropwise over $2 \mathrm{~h}$, and the reaction mixture was stirred at room temperature overnight. The mixture was concentrated and then partitioned between $\mathrm{CH}_{2} \mathrm{Cl}_{2}(20 \mathrm{~mL})$ and $5 \%$ hydrochloric acid $(2 \times 20 \mathrm{~mL})$. The organic layer was washed with brine $(20 \mathrm{~mL})$, dried over $\mathrm{MgSO}_{4}$, filtered, concentrated, and purified by flash chromatography on silica gel eluting with a $5: 1 \mathrm{CH}_{2} \mathrm{Cl}_{2} / \mathrm{EtOAc}$ mixture to give $\mathbf{2}$ as a clear oil (25 mg, 10\%): $R_{f}=0.56$ (4:1 EtOAc: $\left.\mathrm{CH}_{2} \mathrm{Cl}_{2}\right) ;[a]_{\mathrm{D}}{ }^{20}-16.3(c 0.13, \mathrm{MeOH}) ;{ }^{1} \mathrm{H}$ NMR $\left(\mathrm{CDCl}_{3}, 400 \mathrm{MHz}\right) \delta 1.37(\mathrm{~d}, J=7.2 \mathrm{~Hz}, 3 \mathrm{H}), 2.39(\mathrm{dd}, J=16.1,2.9 \mathrm{~Hz}, 1 \mathrm{H}), 2.81-3.07(\mathrm{~m}$, $2 \mathrm{H}), 8.22(\mathrm{~s}, 1 \mathrm{H}) ;{ }^{13} \mathrm{C} \mathrm{NMR}\left(\mathrm{CDCl}_{3}, 100 \mathrm{MHz}\right) \delta 16.5,36.2,37.6,176.4,180.7$; HRMS (ESI-TOF) calcd for $\mathrm{C}_{5} \mathrm{H}_{8} \mathrm{NO}_{2}(\mathrm{M}+\mathrm{H})^{+} 114.0550$, observed 114.0548.

\section{(2E,4E)-N-[(S)-1-Phenylbutyl]hexa-2,4-dienamide (6)}

Sorbic acid (50 mg, $0.45 \mathrm{mmol}, 1.20$ equiv) was added to a solution of (S)-1phenylbutylamine (55 mg, $0.37 \mathrm{mmol}, 1.00$ equiv) and TBTU (155 mg, $0.48 \mathrm{mmol}, 1.30$ equiv) in DMF ( $5 \mathrm{~mL})$ followed by addition of $N, N$-diisopropylethylamine $(162 \mu \mathrm{L}, 120 \mathrm{mg}$, 
$0.93 \mathrm{mmol}, 2.50$ equiv), and the mixture was stirred under $\mathrm{N}_{2}$ for $20 \mathrm{~h}$. The solvent was removed in vacuo, and the resulting residue was purified by flash chromatography on silica gel eluting with a 1:1 Hex/EtOAc solvent to give 6 as a light yellow solid (66 mg, 73\%): $R_{f}$ $=0.56(1: 1 \mathrm{Hex}:$ EtOAc $) ;[a]_{\mathrm{D}}{ }^{24}-136.2\left(c 1.00, \mathrm{CHCl}_{3}\right) ;{ }^{1} \mathrm{H} \mathrm{NMR}\left(\mathrm{CDCl}_{3}, 400 \mathrm{MHz}\right) \delta$ $0.90(\mathrm{t}, J=7.3 \mathrm{~Hz}, 3 \mathrm{H}), 1.18-1.42(\mathrm{~m}, 2 \mathrm{H}), 1.70-1.87(\mathrm{~m}, 5 \mathrm{H}), 5.05(\mathrm{q}, J=7.7 \mathrm{~Hz}, 1 \mathrm{H})$, $5.79(\mathrm{~d}, J=15.0 \mathrm{~Hz}, 1 \mathrm{H}), 5.95-6.23(\mathrm{~m}, 3 \mathrm{H}), 7.10-7.38(\mathrm{~m}, 6 \mathrm{H}) ;{ }^{13} \mathrm{C} \mathrm{NMR}\left(\mathrm{CDCl}_{3}, 100\right.$ MHz) $\delta 14.5,17.9,19.5,38.4,52.5,122.5,125.9,127.5,127.7,129.3,130.5,136.8,140.6$, 142.7, 165.7; HRMS (ESI-TOF) calcd for $\mathrm{C}_{16} \mathrm{H}_{22} \mathrm{NO}(\mathrm{M}+\mathrm{H})^{+} 244.1696$, observed 244.1704 .

\section{Enzyme Purification}

Carboxyltransferase from Staphylococcus aureus was purified as previously described. ${ }^{17}$ Briefly, the genes encoding the $a$ - and $\beta$-subunits of carboxyltransferase were placed in a minioperon such that the $\mathrm{N}$-terminus of the $a$-subunit contained a His tag. The genes were overexpressed, and the protein was purified using nickel affinity chromatography followed by gel-filtration chromatography.

\section{Crystallization and Data Collection}

Crystals were obtained by sitting drop vapor diffusion at $22{ }^{\circ} \mathrm{C}$ using a solution of 16 $\mathrm{mg} / \mathrm{mL}$ carboxyltransferase and $0.5 \mathrm{mM}$ moiramide $\mathrm{B}$. The crystallization condition contained a reservoir solution of 0.1 M MES (pH 5.0) and 1.6 $\mathrm{M} \mathrm{NH}_{4} \mathrm{SO}_{4}$. The sitting drop contained a well:protein volume ratio of 2:2 $\mu \mathrm{L}$. Crystals appeared after 1-2 weeks and were cryoprotected with a $20 \%(\mathrm{v} / \mathrm{v})$ ethylene glycol/reservoir solution, and then that solution was mixed with crystal mother liquor in a 1:1 ratio. The crystal was submerged in the cryoprotectant and then immediately flash-cooled in liquid nitrogen. X-ray diffraction data were collected to $2.6 \AA$ at Advanced Photon Source beamline NE-CAT 24-ID-E equipped with the ADSC Q315r detector. The images were processed using the XDS program suite ${ }^{18}$ and scaled using the Aimless program. ${ }^{19}$ Data collection and refinement statistics are listed in Table 1.

\section{Crystal Structure Determination}

The molecular replacement procedure was applied to locate a solution using MOLREP. ${ }^{20} \mathrm{~A}$ carboxyltransferase subunit of ACC from $S$. aureus (Protein Data Bank entry 2F9I) was used as a search model. The positioned MR model was refined using the maximum likelihood refinement in REFMAC ${ }^{20}$ with the TLS parameters generated by the TLSMD server. ${ }^{21} \mathrm{~A}$ difference Fourier map unambiguously revealed the presence of the inhibitor between the $a$ and $\beta$-chains (Figure 2a). The final model consists of residues 2-17 and 30-314 for the $a$ chain, residues 29-241 and 247-283 for the $\beta$-chain, one $\mathrm{Zn}^{2+}$ cation, one inhibitor molecule, three sulfate anions, one ethylene glycol molecule, and 21 water molecules. $\mathrm{Coot}^{20}$ was used for model building throughout the refinement.

\section{Kinetic Assays}

Carboxyltransferase activity was measured in the reverse, nonphysiological direction and was determined spectrophotometrically by measuring the production of acetyl-CoA using 
citrate synthase and malate dehydrogenase and following the reduction of $\mathrm{NAD}^{+}$at 340 $\mathrm{nm} .{ }^{22}$ Each reaction mixture contained $0.12 \mathrm{mg} / \mathrm{mL}$ malate dehydrogenase, $0.05 \mathrm{mg} / \mathrm{mL}$ citrate synthase, $0.5 \mathrm{mM} \mathrm{NAD}{ }^{+}, 0.01 \mathrm{mM}$ malic acid, $0.6 \mathrm{mg} / \mathrm{mL}$ bovine serum albumin (BSA), and $100 \mathrm{mM}$ Tris (pH 8.0). All reactions had constant malonyl-CoA and biocytin (a biotin analogue) substrate concentrations of $150 \mu \mathrm{M}$ and $6 \mathrm{mM}$, respectively. A final concentration of $50 \mathrm{nM}$ of compounds 1 and 3-7 was added to measure the effect on activity. All reactions were conducted in a total of $0.5 \mathrm{~mL}$ in a $1 \mathrm{~cm}$ path length quartz cuvette, and all reactions were initiated by the addition of enzyme and measured in triplicate. Spectrophotometric data were collected using an Agilent Cary $60 \mathrm{UV}$-vis spectrophotometer interfaced with a personal computer with a data acquisition program supplied by Agilent.

\section{Whole-Cell Growth Assays}

A culture of E. coli strain JM109 was grown overnight in Luria-Bertani medium at $37{ }^{\circ} \mathrm{C}$. Culture tubes containing $2 \mathrm{~mL}$ of fresh medium were inoculated with $10 \mu \mathrm{L}$ of the saturated E. coli culture. Compounds 1 and 3-7 were dissolved in 100\% DMSO to achieve a $5 \mathrm{mM}$ stock solution and inoculated into tubes to generate final concentrations of $50 \mu \mathrm{M}$. After inoculation, the culture tubes were incubated for $4 \mathrm{~h}$ at $37^{\circ} \mathrm{C}$. Optical density (OD) readings were measured at $600 \mathrm{~nm}$ in $1 \mathrm{~mL}$ plastic cuvettes. Spectrophotometric data were collected using an Agilent Cary $60 \mathrm{UV}$-vis spectrophotometer.

\section{RESULTS}

\section{Overall Structure of Moiramide B Bound to Carboxyltransferase}

We previously described the synthesis of moiramide B on a milligram scale. ${ }^{16}$

Carboxyltransferase from $S$. aureus ( $\mathrm{SaCT}$ ) was cocrystallized with the synthetic moiramide $B$. The structure of moiramide B bound to CT was determined and refined to a resolution of 2.6 A. Data collection statistics and refinement details are listed in Table 1. A difference Fourier map clearly established the presence of the moiramide B molecule in the active site of $\mathrm{CT}$, which is located at the interface of the $a$ - and $\beta$-subunits of the heterotetramer (Figure 2a). ${ }^{17}$ Binding in the active site is consistent with the observation that moiramide B exhibits competitive inhibition with respect to the substrates. ${ }^{15}$

Pohlmann et al. identified four characteristic fragments of moiramide B: (1) the pyrrolidinedione (succinimide) headgroup, (2) the L-valine-derived $\beta$-ketoamide, (3) $\beta$ amino acid $\beta$-phenylalanine, and (4) the unsaturated fatty acid chain (Figure 1A). ${ }^{21} \mathrm{~A}$ key observation from the structure of moiramide B bound to $S a \mathrm{CT}$ is that the $a$-carbon between the ketone and amide is $\mathrm{sp}^{2}$-hybridized. It is not clear whether this is the enol tautomer of the $\beta$-ketoamide or the enolate anion [compound 2 (Figure 1B and Figure S1)]. During refinement, it became apparent that the fragment of moiramide $\mathrm{B}$ proximal to the $\mathrm{sp}^{2}$ carbon (particularly the L-valine side chain) would not fit the density with moiramide B in the keto form. In contrast, the enol/enolate of moiramide B readily fits the observed electron density. It is worth noting that for andrimid (the homologue of moiramide $\mathrm{B}$ with two additional carbons in the fatty acid chain), the $\mathrm{p} K_{\mathrm{a}}$ of the $\beta$-ketoamide has been determined to be 6.8 in 
$60 \%$ methanol in water. ${ }^{23}$ Thus, enolate formation and stabilization in the active site of the enzyme could be a facile process at physiological $\mathrm{pH}$ values.

The enolate of moiramide B is capable of hydrogen bonding interactions with CT that are stronger than those of the neutral $\beta$-ketoamide (Figure 2b,c). Most of the carbonyl and peptidic NH groups in moiramide B form one or more hydrogen bonds with residues from both the $a$ - and $\beta$-subunits of CT. This contradicts an earlier report that andrimid, and by inference moiramide $\mathrm{B}$, interacts solely with the $\beta$-subunit of $\mathrm{CT}^{24}$ Each of the residues in CT that hydrogen bond with moiramide B is conserved between Gram-negative and Grampositive bacteria, which is consistent with the broad-spectrum antibacterial activity of moiramide B. ${ }^{14,15,25,26}$ Conserved residues in a protein suggest they are important for the function of the protein. The observation that moiramide B interacts with conserved residues also decreases the probability of a bacterium mutating one of these residues to become resistant to moiramide $\mathrm{B}$. A detailed analysis of the structural features for each of the fragments of moiramide B (Figure 1A) follows.

\section{Pyrrolidinedione Fragment}

The crystal structure of moiramide B bound to carboxyltransferase reveals why the pyrrolidinedione is such a good isosteric and isoelectronic surrogate for the enolate of biotin. The partial double-bond character of the succinimidyl amides lends higher electron density to the oxygen (cf., a cyclopentadione), providing for a stronger interaction in the oxyanion hole. Sterically, the succinimide is a good fit, explaining why Pohlmann's glutamide analogues had little activity (vide infra). ${ }^{21}$ In CT, oxyanion holes are needed to stabilize the enolates that form from each substrate during catalysis. In $\mathrm{SaCT}$, the amide protons of adjacent glycine residues, Gly199 and Gly200 in the $a$-subunit [Gly199(a) and Gly200(a), respectively] and Gly207 and Gly208 in the $\beta$-subunit [Gly207( $\beta$ ) and Gly208( $\beta)$, respectively], serve as hydrogen bond donors, constituting the oxyanion holes that stabilize the enolate and imidate anions in acetyl-CoA and biotin, respectively (Figure S2). ${ }^{17}$ It is interesting to note that the $\mathrm{C} 2(=\mathrm{O})$ group in the pyrrolidinedione headgroup (fragment 1 , numbering according to Needham et al. ${ }^{14}$ ) interacts directly with the amide hydrogen of Gly208( $\beta$ ) (Figure 2c). The C5(=O) group interacts with the hydroxyl group of Ser198, which is next to the oxyanion hole residue Gly199(a). On the basis of the orientation of moiramide B in the active site of CT, the keto groups of the pyrrolidinedione headgroup have allowed moiramide B to take advantage of the structural features of the enzyme, resulting in a potent inhibitor of $\mathrm{CT}$ that is also bactericidal.

The crystal structure of moiramide B bound to the CT complex helps to explain the results of previous structure-activity studies. ${ }^{26}$ Pohlmann et al. found that six-membered piperidinedione (glutamide) analogues of moiramide B did not exhibit any antibacterial activity. The imide carbonyls likely do not have the appropriate orientation to hydrogen bond with the active site amino acids. Moreover, Pohlmann et al. found that an increase in the bulk and hydrophobicity of substituents at the succinimide nitrogen resulted in a progressive decrease in both the $\mathrm{IC}_{50}$ and MIC values, ${ }^{26}$ indicating that the size of this moiety had an impact on enzyme inhibition and, thus, antibacterial activity. 
The crucial positioning of the pyrrolidinedione headgroup in the oxyanion holes is also corroborated by a mutation in carboxyltransferase that provides resistance to andrimid. Pantoea agglomerans, the bacterium that produces andrimid, is resistant to the antibacterial properties of its metabolite, because of a mutation in the $\beta$-subunit (M203L and T206L in $E$. coli and $S$. aureus carboxyltransferase, respectively). ${ }^{27}$ The Thr206 residue is adjacent to one of the residues in the $\beta$-subunit (Gly207 and Gly208) that form the oxyanion hole. Therefore, the T206L mutation could cause a local conformational change that weakens or eliminates the binding of andrimid (and by inference moiramide B) to the enzyme.

The structure-activity relationships in Pohlmann et al. indicated that the (4S)-methyl group on the pyrrolidinedione moiety was very important for antibacterial activity. Removal of the methyl group, inclusion of two methyl groups at position 4, or replacement with an ethyl group resulted in a total loss of activity. ${ }^{26,28}$ Thus, the methyl group contributes to the potency of moiramide B as an inhibitor of CT. However, the crystal structure does not provide an immediate explanation for this (e.g., nestling in a hydrophobic pocket of the appropriate size).

Because moiramide B was synthetic in origin, we had intermediates that could be readily accessed to probe the significance of the (4S)-methyl group, as well as the other structural characteristics of moiramide B. Compounds that are representative of the fragments of moiramide B (Figure 3) were tested for enzyme inhibition. Succinimide (3) is commercially available, and (3S)-methyl succinimide (4) was synthesized from an intermediate precursor during the synthesis of moiramide B (compound $\mathbf{1}$ ). ${ }^{16}$ Compounds 5 and $\mathbf{6}$ were also intermediates generated during the synthesis of moiramide B (compound 1). ${ }^{16}$ Compound 7 , a stand-alone version of the "tail" fragment, was synthesized for this analysis.

The initial velocity of carboxyltransferase was measured in the presence of each of the compounds at $50 \mathrm{nM}$, while the concentrations of substrates malonyl-CoA and biocytin were held constant at a subsaturating level (Figure 4a and Table S1). Succinimide (compound 3) was, within error, not an inhibitor of carboxyltransferase. However, addition of the (4S)methyl substituent (compound 4) resulted in a 50\% decrease in CT activity compared to that with the succinimide and an overall $65 \%$ decrease in activity when compared to the control. Thus, the methyl group contributes significantly to the inhibition of carboxyltransferase by moiramide B.

In the absence of structural evidence of the role of the methyl group, we propose three possible functions. First, the weakly electron-donating methyl group may contribute to the oxyanion character via an inductive effect, thereby strengthening the hydrogen bond interactions with the active site amino acids. Second, the reduced energy for desolvation of the methyl group (cf., a hydrogen) could increase binding affinity. ${ }^{29}$ Finally, the methyl group likely exerts an influence on the conformation of the pyrrolidinedione ring, already demonstrated to be key to effective binding. The observation that the methyl group in compound $\mathbf{4}$ leads to significant inhibitory activity relative to compound $\mathbf{3}$ is consistent with each of these hypotheses or some combination thereof (Figure 4a). 


\section{L-Valine-Derived $\beta$-Ketoamide Fragment}

There is a hydrophobic binding pocket for the side chain of the valine residue of moiramide

B. The pocket is composed of Met170( $\beta)$ and Val235( $\beta)$, as well as Ile221( $a)$ and

Leu229(a) (Figure 5a). The binding pocket for the valine residue is not present in the unliganded structure of SaCT. ${ }^{17}$ The pocket could form as a result of moiramide B binding, or moiramide B binds to the conformation with the binding pocket that is in equilibrium with the unliganded conformation. Nonetheless, formation of the pocket closes off the binding site from the solvent (Figure $5 \mathrm{~b}, \mathrm{c}$ ). An $a$-helix/loop motif in the $\beta$-subunit, which is composed of residues Ala231-Asn241 ( $a$-helix) and Glu242-Asp247 (loop), undergoes a significant conformational change as a result of ligand binding (Figure 6). The loop segment becomes disordered with no observable electron density in the liganded structure. The largest movement $(10.7 \AA)$ is observed for the corresponding $\mathrm{C} a$ atom of Asn241 of the native and liganded structures.

In addition to the movement of the $a$-helix/loop motif, a short stretch (Ser165-Arg169) of a $\beta$-sheet in the $\beta$-subunit moves slightly compared to the unliganded structure when moiramide B is bound to $\mathrm{SaCT}$. This conformational change allows for the formation of hydrogen bonds between the carbonyl of Gly166 and both of the peptidic NH groups of valine and $\beta$-phenylalanine fragments, as well as a hydrogen bond between the peptidic $\mathrm{NH}$ group of Gly168 and the carbonyl oxygen of the L-valine $\beta$-ketoamide region (Figure 2c).

\section{$\beta$-Phenylalanine Fragment}

The comparison of CT inhibition by compounds $\mathbf{1}$ and 3-7 in Figure 4a indicates that while the attachment of the L-valine group (compound 5) increased the level of CT inhibition only slightly, the addition of the $\beta$-phenylalanine moiety (compound $\mathbf{6}$ ) increased the level of inhibition an additional $15 \%$. This suggests that the $\beta$-phenylalanine moiety is an important component for increasing the binding affinity of moiramide $\mathrm{B}$ for the enzyme. As the number of hydrogen bonds increases with the addition of each "backbone amide" (i.e., the sequential addition of $\mathrm{L}$-valine and $\beta$-phenylalanine residues), so does the binding affinity (Figure 2c).

There is no defined hydrophobic binding pocket for the phenyl ring of the $\beta$-phenylalanine residue. Indeed, there are no close interactions with any amino acids of the enzyme. Maybe, like the methyl group on the pyrrolidinedone ring, the phenyl side chain has a desolvation effect, leading to a higher affinity for carboxyltransferase. More importantly, this $\beta$-amino acid presents a favorable spatial relationship between the amide $\mathrm{NH}$ group and the $\mathrm{C}=\mathrm{O}$ group to form hydrogen bonds with Gly166( $\beta$ ). Incorporation of an $a$-phenylalanine residue might afford the desolvation effect, but the $\mathrm{NH}$ group would be in the wrong location to engage in a productive hydrogen bond with Gly166( $\beta)$. Moreover, we propose that in an $a$ phenylalanine analogue, the phenyl group would provide steric interference for the oxyanion hole in the $a$-subunit (residues 206-208), as well as residues 231-233 of the $\beta$-subunit loop that moves in response to moiramide B binding. 


\section{Unsaturated Fatty Acid Fragment}

The unsaturated fatty acid tail interacts with Met134( $\beta)$ and Leu229( $\beta)$, and with Met179 $(a)$. These interactions are not particularly strong as indicated by the higher $B$ factors for the atoms in the unsaturated fatty acid tail compared to the atoms of the other fragments of moiramide B. Moreover, Figure 4a shows that there is little difference in CT inhibitory activity between compounds $\mathbf{6}$ and $\mathbf{1}$, indicating little effect of the addition of the fatty acyl tail. Compound $\mathbf{7}$ itself, embodying the fatty acyl tail and a phenylamide functionality, exhibited no inhibition of CT, yet the bacterial cell expends considerable metabolic energy incorporating this moiety into moiramide B. ${ }^{24}$

The role of the unsaturated fatty acid becomes readily apparent if the antibacterial activities of compounds 1 and 3-7 are tested (Figure $4 \mathrm{~b}$ ). A final concentration of $50 \mu \mathrm{M}$ for each compound was added to culture media inoculated with $E$. coli and incubated for $4 \mathrm{~h}$. With the exception of moiramide B itself, none of the compounds exhibited any antibacterial activity (Figure 4b, Figure S3, and Table S2). Even though compounds 4-6 all inhibited CT significantly (Figure 4a), they did not display any antibacterial activity at a concentration of $50 \mu \mathrm{M}$ (Figure 4B). The only difference between compound 6 and moiramide B (compound 1) is the incorporation of the fatty acyl tail. Therefore, it is tempting to suggest that the role of the fatty acyl tail in the mechanism of action of moiramide B is transport of the molecule into the bacterial cell.

\section{DISCUSSION}

Given the dominant role of natural products among clinically useful antibiotics, it is instructive to determine in detail how the only natural product inhibitor of acetyl-CoA carboxylase exerts its antibacterial effect. First, the observation that the bound form of the drug appears to be the enolate is important. The fact that the drug binds in its enolate form helps to explain the high affinity for the enzyme and by inference its potency as an antibacterial agent. The enolate form of moiramide B is stabilized in the oxyanion hole of carboxyltransferase, which is consistent with the fact that the enzyme must stabilize the enolates that form in both substrates, acetyl-CoA and biotin, during catalysis. While this finding has implications for understanding the catalytic mechanism of carboxyltransferase, on a more practical level, it also provides direction for the design of future inhibitors of carboxyltransferase. Second, the crystal structure reveals how nature expropriated the oxyanion holes in carboxyltransferase to utilize a molecule with the appropriate structural components to behave as a potent enzyme inhibitor. In nature's version of structure-based drug design, a methyl pyrrolidinedione functionality evolved to inhibit carboxyltransferase by binding in the oxyanion holes found in both the $a$ - and $\beta$-subunits. Third, in an example of nature mimicking a common technique in medicinal chemistry, the addition of a methyl group to the succinimide headgroup resulted in a significant increase in binding affinity. Thus, the evolution of moiramide B utilized two common approaches used in anthropogenic drug design. It will be interesting to see if these scaffolds can also be used in the design of inhibitors of human acetyl-CoA carboxylase II, which has a mechanism similar to that of the bacterial enzyme (i.e., it also utilizes two oxyanion holes for catalysis). The mitochondrial 
isoform (or acetyl-CoA carboxylase II) is involved in regulating fatty acid oxidation and is a target for anti-obesity agents. ${ }^{30}$

While inhibition of the target enzyme is certainly important for an antibacterial agent, the ability to gain entry into the bacterium is equally important. The studies here show that the unsaturated fatty acid tail of moiramide B plays no role in inhibiting carboxyltransferase but is critical for the molecule to enter the bacterial cell. Thus, it is instructional to see how nature incorporated two distinct chemical moieties, a methyl pyrrolidinedione and an unsaturated fatty acid, into a single molecule to solve two distinct biological problems, enzyme inhibition and bacterial membrane transport. The lack of involvement of the unsaturated tail in binding to $\mathrm{CT}$ points to the possibility of modifying moiramide $\mathrm{B}$ for other applications. Conjugation of compound 6 with a fluorescent dye or moieties containing nuclides for positron emission tomography can lead to the development of molecular imaging agents for selectively detecting and imaging infectious diseases. ${ }^{31-33}$

The presence of the unsaturated fatty acid tail, along with the phenyl and valine side chains, makes moiramide B a very hydrophobic molecule. This is not characteristic of clinically useful molecules that have broad-spectrum antibacterial activity, which tend to be more polar. ${ }^{34}$ For example, broad-spectrum antibiotics typically have a $\log \mathrm{P}$ (a measure of hydrophobicity) of less than zero (i.e., hydrophilic), whereas the $\log P$ for moiramide B is 2.9. In fact, moiramide $B$ has only one characteristic of broad-spectrum antibiotics, namely a molecular weight of $<600 \mathrm{Da}(457.6 \mathrm{Da})$. The results described in this report provide a blueprint from which to synthesize derivatives of moiramide B to increase solubility without affecting (or maybe even increasing) potency and chemical stability. Lastly, the lessons learned from analyzing how the natural process of evolution led to moiramide B will allow for the development of new antibacterial agents against a novel target molecule, acetyl-CoA carboxylase.

\title{
Supplementary Material
}

Refer to Web version on PubMed Central for supplementary material.

\section{Acknowledgments}

Funding

This work is based upon research conducted at the Northeastern Collaborative Access Team beamlines, which are funded by the National Institute of General Medical Sciences from the National Institutes of Health (NIH) (P41 GM103403). The Pilatus 6M detector on beamline 24-ID-C is funded by a NIH-ORIP HEI grant (S10 RR029205). This research used resources of the Advanced Photon Source, a U.S. Department of Energy (DOE) Office of Science User Facility operated for the DOE Office of Science by Argonne National Laboratory under Contract DEAC02-06CH11357.

\section{ABBREVIATIONS}

\author{
ACC acetyl-CoA carboxylase \\ BC biotin carboxylase \\ BCCP biotin carboxyl carrier protein
}




$\begin{array}{ll}\text { CT } & \text { carboxyltransferase } \\ \text { ESI-TOF } & \text { electrospray ionization time-of-flight } \\ \text { HRMS } & \text { high-resolution mass spectrometry } \\ \text { NMR } & \text { nuclear magnetic resonance } \\ \text { rmsd } & \text { root-mean-square deviation } \\ \text { SaCT } & \text { S. aureus carboxyltransferase } \\ \text { TMS } & \text { tetramethylsilane }\end{array}$

\section{References}

1. Walsh CT, Wencewicz TA. Prospects for new antibiotics: a molecule-centered perspective. J Antibiot. 2014; 67:7-22. [PubMed: 23756684]

2. von Nussbaum F, Brands M, Hinzen B, Weigand S, Häbich D. Antibacterial Natural Products in Medicinal Chemistry - Exodus or Revival? Angew Chem, Int Ed. 2006; 45:5072-5219.

3. Heath RJ, Rock CO. Fatty acid biosynthesis as a target for novel antibacterials. Curr Opin Invest Drugs. 2004; 5:146-153.

4. Zhang YM, White SW, Rock CO. Inhibiting bacterial fatty acid synthesis. J Biol Chem. 2006; 281:17541-17544. [PubMed: 16648134]

5. Campbell JW, Cronan JE Jr. Bacterial fatty acid biosynthesis: targets for antibacterial drug discovery. Annu Rev Microbiol. 2001; 55:305-332. [PubMed: 11544358]

6. Davis MS, Solbiati J, Cronan JE Jr. Overproduction of acetyl-CoA carboxylase activity increases the rate of fatty acid biosynthesis in Escherichia coli. J Biol Chem. 2000; 275:28593-28598. [PubMed: 10893421]

7. Cronan JE Jr, Waldrop GL. Multi-subunit acetyl-CoA carboxylases. Prog Lipid Res. 2002; 41:407435. [PubMed: 12121720]

8. Broussard TC, Price AE, Laborde SM, Waldrop GL. Complex formation and regulation of Escherichia coli acetyl-CoA carboxylase. Biochemistry. 2013; 52:3346-3357. [PubMed: 23594205]

9. Knowles JR. The mechanism of biotin-dependent enzymes. Annu Rev Biochem. 1989; 58:195-221. [PubMed: 2673009]

10. Waldrop GL, Holden HM, St Maurice M. The enzymes of biotin-dependent $\mathrm{CO}_{2}$ metabolism: what structures reveal about their reaction mechanisms. Protein Sci. 2012; 21:1597-1619. [PubMed: 22969052]

11. Miller JR, Dunham S, Mochalkin I, Banotai C, Bowman M, Buist S, Dunkle B, Hanna D, Harwood HJ, Huband MD, Karnovsky A, Kuhn M, Limberakis C, Liu JY, Mehrens S, Mueller WT, Narasimhan L, Ogden A, Ohren J, Prasad JV, Shelly JA, Skerlos L, Sulavik M, Thomas VH, VanderRoest S, Wang L, Wang Z, Whitton A, Zhu T, Stover CK. A class of selective antibacterials derived from a protein kinase inhibitor pharmacophore. Proc Natl Acad Sci U S A. 2009; 106:1737-1742. [PubMed: 19164768]

12. Mochalkin I, Miller JR, Narasimhan L, Thanabal V, Erdman P, Cox PB, Prasad JV, Lightle S, Huband MD, Stover CK. Discovery of antibacterial biotin carboxylase inhibitors by virtual screening and fragment-based approaches. ACS Chem Biol. 2009; 4:473-483. [PubMed: 19413326]

13. Cheng CC, Shipps GW Jr, Yang Z, Sun B, Kawahata N, Soucy KA, Soriano A, Orth P, Xiao L, Mann P, Black T. Discovery and optimization of antibacterial AccC inhibitors. Bioorg Med Chem Lett. 2009; 19:6507-6514. [PubMed: 19875284]

14. Needham J, Kelly MT, Ishige M, Andersen RJ. Andrimid and moiramides A-C, metabolites produced in culture by a marine isolate of the bacterium Pseudomonas fluorescens: Structure elucidation and biosynthesis. J Org Chem. 1994; 59:2058-2063. 
15. Freiberg C, Brunner NA, Schiffer G, Lampe T, Pohlmann J, Brands M, Raabe M, Habich D, Ziegelbauer K. Identification and characterization of the first class of potent bacterial acetyl-CoA carboxylase inhibitors with antibacterial activity. J Biol Chem. 2004; 279:26066-26073. [PubMed: 15066985]

16. Silvers MA, Robertson GT, Taylor CM, Waldrop GL. Design, synthesis, and antibacterial properties of dual-ligand inhibitors of acetyl-CoA carboxylase. J Med Chem. 2014; 57:8947-8959. [PubMed: 25280369]

17. Bilder P, Lightle S, Bainbridge G, Ohren J, Finzel B, Sun F, Holley S, Al-Kassim L, Spessard C, Melnick M, Newcomer M, Waldrop GL. The structure of the carboxyltransferase component of acetyl-coA carboxylase reveals a zinc-binding motif unique to the bacterial enzyme. Biochemistry. 2006; 45:1712-1722. [PubMed: 16460018]

18. Kabsch W. XDS. Acta Crystallogr, Sect D: Biol Crystallogr. 2010; 66:125-132. [PubMed: 20124692]

19. Evans PR, Murshudov GN. How good are my data and what is the resolution? Acta Crystallogr, Sect D: Biol Crystallogr. 2013; 69:1204-1214. [PubMed: 23793146]

20. Collaborative Computational Project, Number 4. The CCP4 suite: programs for protein crystallography. Acta Crystallogr, Sect D: Biol Crystallogr. 1994; 50:760-763. [PubMed: 15299374]

21. Painter J, Merritt EA. TLSMD web server for the generation of multi-group TLS models. J Appl Crystallogr. 2006; 39:109-111.

22. Blanchard CZ, Waldrop GL. Overexpression and kinetic characterization of the carboxyltransferase component of acetyl-CoA carboxylase. J Biol Chem. 1998; 273:19140-19145. [PubMed: 9668099]

23. Fredenhagen A, Tamura SY, Kenny PTM, Komura H, Naya Y, Nakanishi K, Nishiyama K, Sugiura M, Kita H. Andrimid, a new peptide antibiotic produced by an intracellular bacterial symbiont isolated from a brown planthopper. J Am Chem Soc. 1987; 109:4409-4411.

24. Jin M, Fischbach MA, Clardy J. A biosynthetic gene cluster for the acetyl-CoA carboxylase inhibitor andrimid. J Am Chem Soc. 2006; 128:10660-10661. [PubMed: 16910643]

25. Freiberg C, Pohlmann J, Nell PG, Endermann R, Schuhmacher J, Newton B, Otteneder M, Lampe T, Habich D, Ziegelbauer K. Novel bacterial acetyl coenzyme A carboxylase inhibitors with antibiotic efficacy in vivo. Antimicrob Agents Chemother. 2006; 50:2707-2712. [PubMed: 16870762]

26. Pohlmann J, Lampe T, Shimada M, Nell PG, Pernerstorfer J, Svenstrup N, Brunner NA, Schiffer G, Freiberg C. Pyrrolidinedione derivatives as antibacterial agents with a novel mode of action. Bioorg Med Chem Lett. 2005; 15:1189-1192. [PubMed: 15686939]

27. Liu X, Fortin PD, Walsh CT. Andrimid producers encode an acetyl-CoA carboxyltransferase subunit resistant to the action of the antibiotic. Proc Natl Acad Sci U S A. 2008; 105:1332113326. [PubMed: 18768797]

28. McWhorter W, Fredenhagen A, Nakanishi K, Komura H. Stereocontrolled synthesis of andrimid and a structural requirement for the activity. J Chem Soc, Chem Commun. 1989:299-301.

29. Schönherr H, Cernak T. Profound methyl effects in drug discovery and a call for new C-H methylation reactions. Angew Chem, Int Ed. 2013; 52:12256-12267.

30. Wakil SJ, Abu-Elheiga LA. Fatty acid metabolism: target for metabolic syndrome. J Lipid Res. 2008; 50(Suppl):S138-S143. [PubMed: 19047759]

31. Bunschoten A, Welling MM, Termaat MF, Sathekge M, van Leeuwen FW. Development and prospects of dedicated tracers for the molecular imaging of bacterial infections. Bioconjugate Chem. 2013; 24:1971-1989.

32. Wang X, Murthy N. Bacterial imaging comes of age. Sci Transl Med. 2014; 6:259fs43.

33. Weinstein EA, Ordonez AA, DeMarco VP, Murawski AM, Pokkali S, MacDonald EM, Klunk M, Mease RC, Pomper MG, Jain SK. Imaging Enterobacteriaceae infection in vivo with ${ }^{18} \mathrm{~F}$ fluorodeoxysorbitol positron emission tomography. Sci Transl Med. 2014; 6:259ra146.

34. O'Shea R, Moser HE. Physicochemical properties of antibacterial compounds: implications for drug discovery. J Med Chem. 2008; 51:2871-2878. [PubMed: 18260614] 

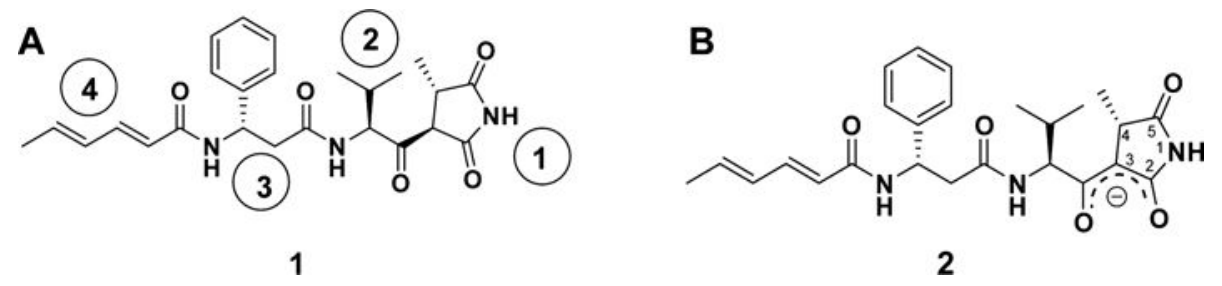

Figure 1.

Structure of moiramide B. (A) Moiramide B (compound 1) can be divided into four fragments: (1) pyrrolidinedione headgroup, (2) L-valine-derived $\beta$-ketoamide, (3) $\beta$-amino acid $\beta$-phenylalanine, and (4) unsaturated fatty acid chain. (B) Enolization between the C2 carbonyl of the pyrrolidinedione headgroup and the carbonyl of L-valine $\beta$-ketoamide provides resonance around $\mathrm{C} 3$ of the pyrrolidinedione headgroup. The acidity of the $a$ hydrogen of this diketone moiety allows for easy abstraction to generate an overall negative charge that is stabilized between these select carbonyls (compound 2). 
a
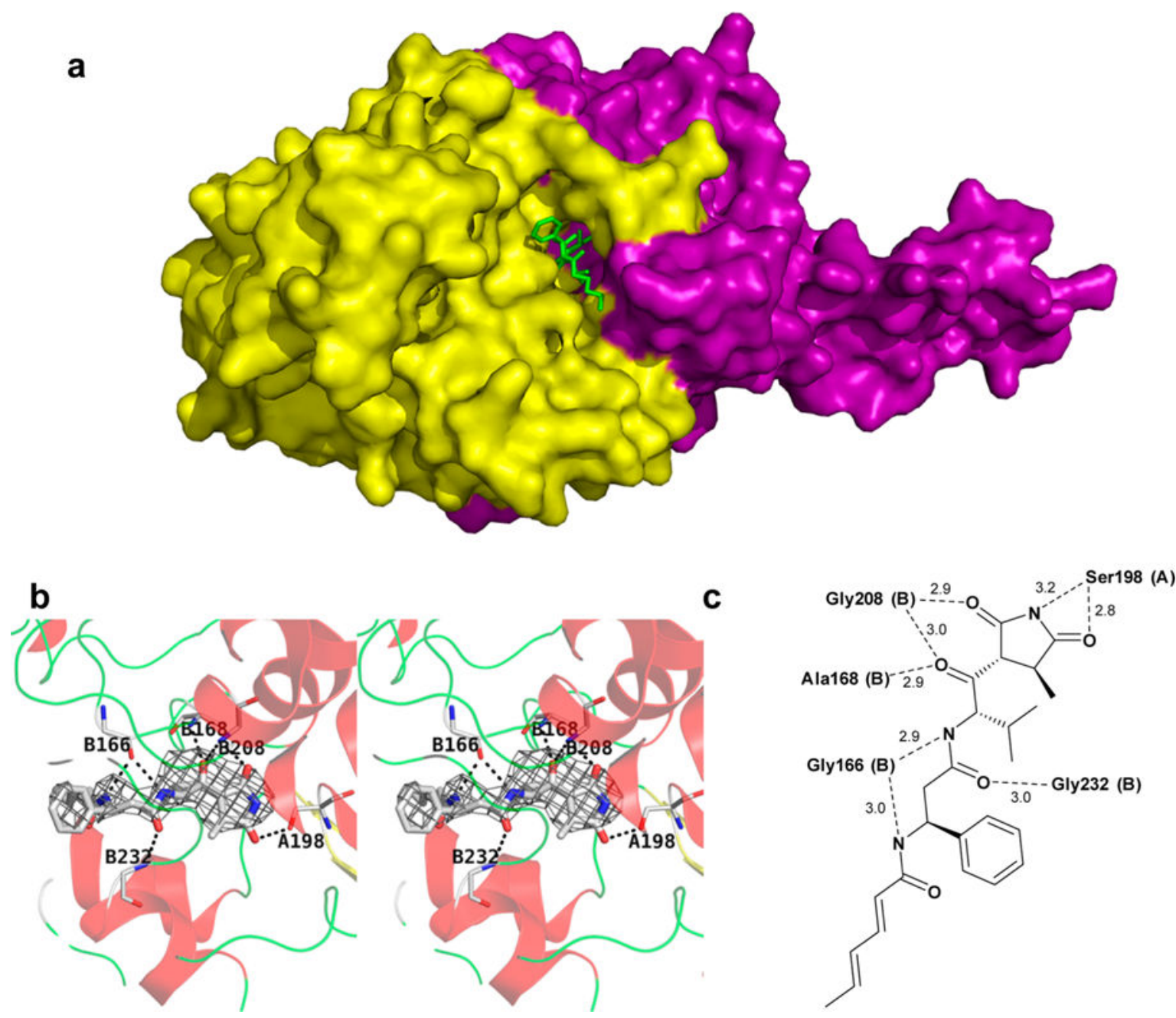

Figure 2.

Moiramide B binds at the subunit interface of carboxyltransferase. (a) Moiramide B binds at the interface of the $\alpha$-subunit (purple) and $\beta$-subunit (gold) of $S$. aureus carboxyltransferase, which is shown as a surface rendering. Moiramide B is represented as green sticks. (b) Stereoview of the moiramide B binding site of $S$. aureus carboxyltransferase. The $F_{\mathrm{o}}-F_{\mathrm{c}}$ electron density map is contoured at $2.5 \sigma$. The map was calculated before inclusion of moiramide B atoms in the model. (c) Schematic diagram showing the interactions occurring between moiramide B and active site residues. Dashes and numbers indicate hydrogen bonds and distance in angstroms. Letters in parentheses indicate the subunit in which the residue is located, A for the $a$-subunit and B for the $\beta$-subunit. 

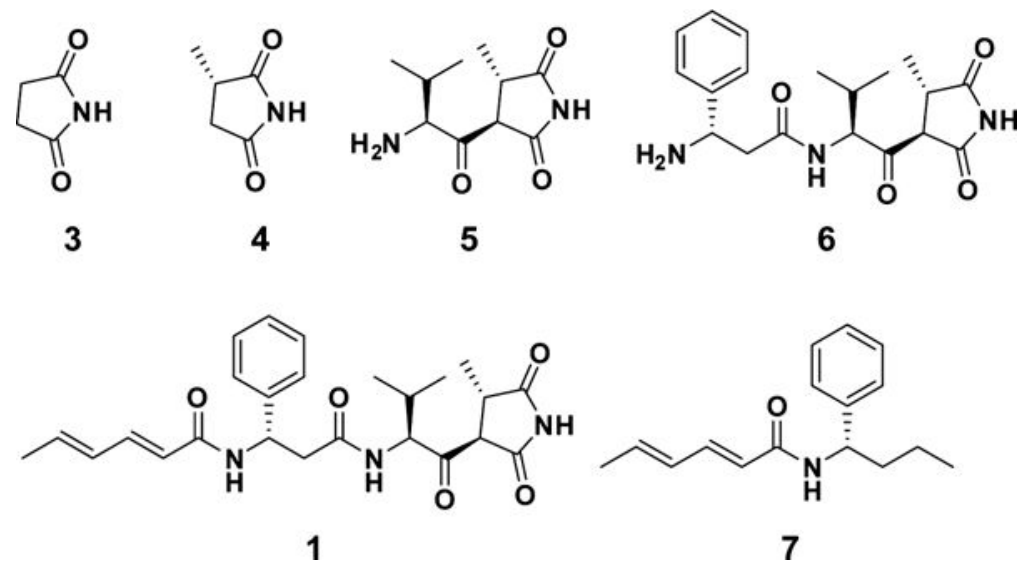

Figure 3.

Structures of the moiramide B intermediates. Succinimide (3), (3S)-methyl-2,5pyrrolidinedione (4), (3S)-L-valine-(4S)-methyl-2,5-pyrrolidinedione (5), $(3 S)$ - $\beta$ phenylalanine-L-valine-(4S)-methyl-2,5-pyrrolidinedione (6), moiramide B (1), and the fatty acyl tail fragment (7). 

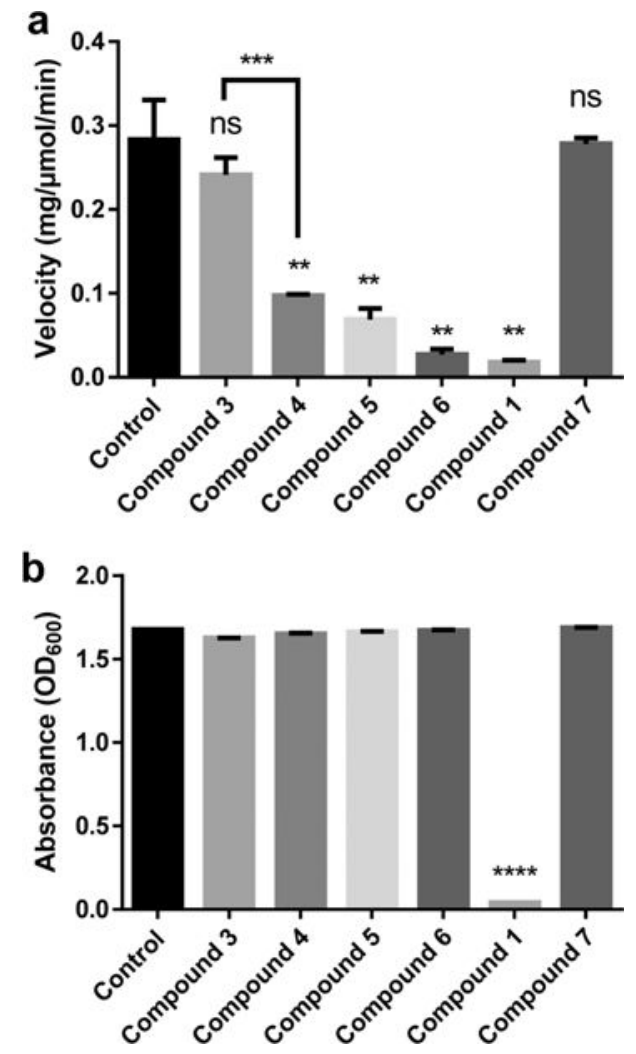

Figure 4.

Biological activity of the structural fragments of moiramide B. (a) Inhibitory activity of compounds 1 and 3-7. Initial velocities of carboxyltransferase were measured in the presence of each compound at $50 \mathrm{nM}$ while the concentrations of the substrates, malonylCoA and biocytin, were held at subsaturating levels (150 $\mu \mathrm{M}$ and $6 \mathrm{mM}$, respectively).

Results were compared to the control (unless otherwise noted) using Student's two-tailed $t$ tests ( \pm standard deviations). ns means not significant. ${ }^{*} p<0.05 ; * * p<0.01 ; * * * p<0.001$. (b) Antibacterial activity of compounds 1 and 3-7. E. coli was inoculated with each compound at a final concentration of $50 \mu \mathrm{M}$ and incubated at $37^{\circ} \mathrm{C}$. After a $4 \mathrm{~h}$ incubation, the absorbance at $600 \mathrm{~nm}$ was measured. Results were compared to the control using Student's two-tailed $t$ tests ( \pm standard deviations). $* * * * p<0.0001$. 

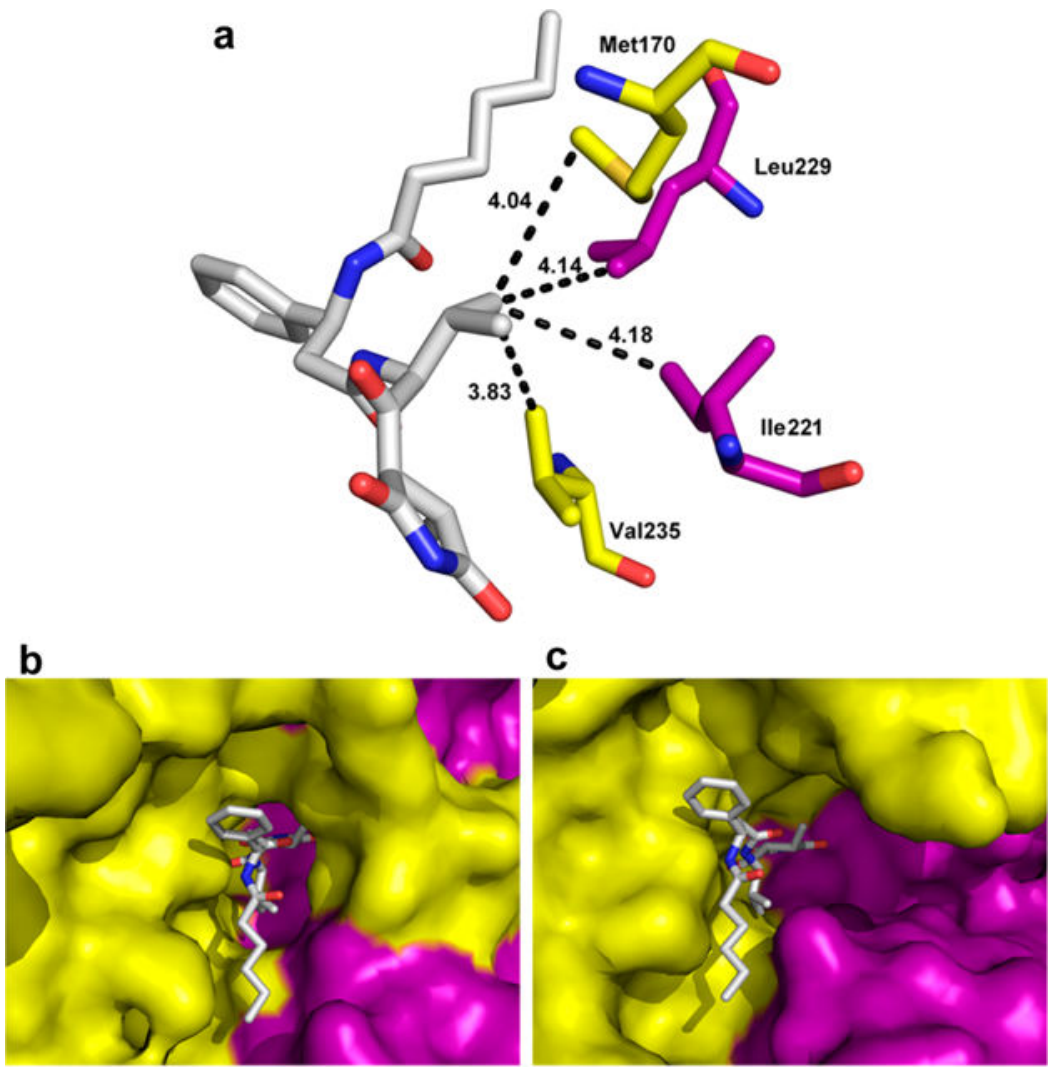

Figure 5.

Hydrophobic binding interactions of moiramide B. (a) Hydrophobic binding pocket for the valine side chain of moiramide B (gray sticks). The residues that form the pocket include Met170( $\beta$ ) and Val235( $\beta$ ) (gold) and Ile221( $a$ ) and Leu229( $a$ ) (purple). Distances are in angstroms. (b) Binding cavity of moiramide B in $S$. aureus carboxyltransferase, which is represented as a surface rendering. The $a$-subunit is colored purple and the $\beta$-subunit gold. (c) Moiramide B ligand from the structure described in this report superimposed on unliganded $S$. aureus carboxyltransferase (Protein Data Bank entry 2F9I). The color coding is the same as in panel B. 


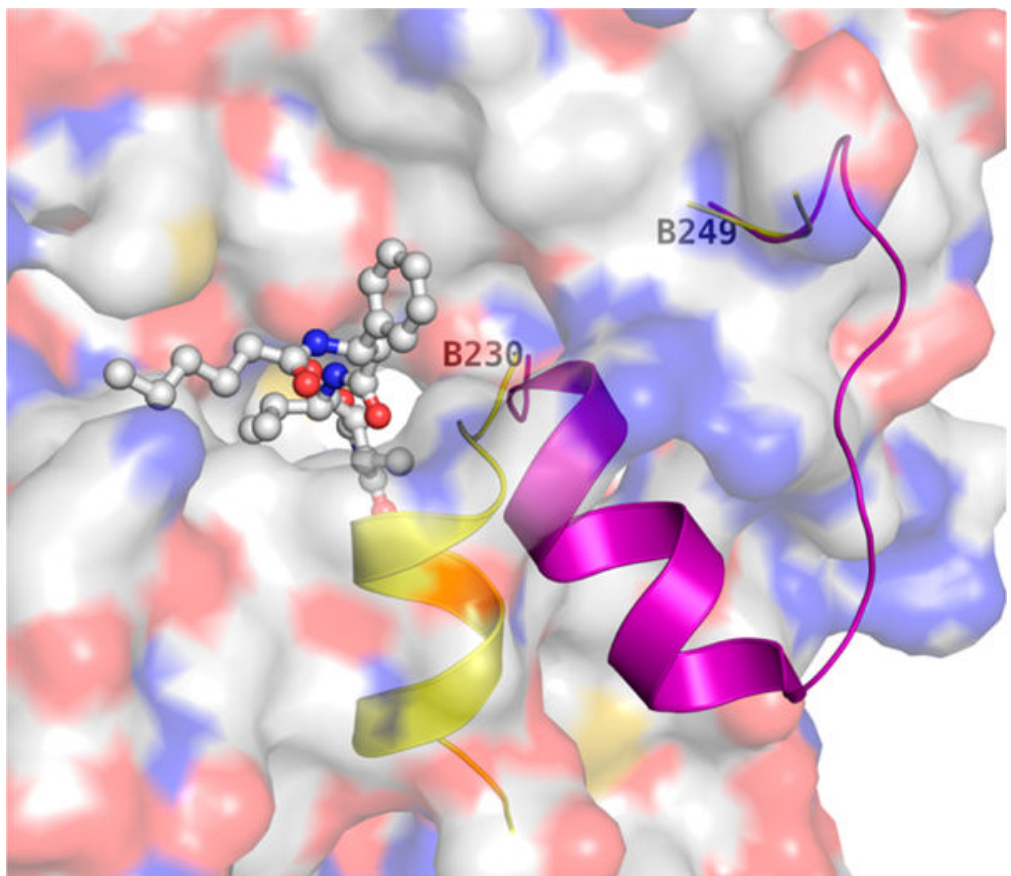

Figure 6.

Movement of the $a$-helix/loop motif in the $\beta$-subunit of carboxyltransferase after the binding of moiramide B. The $a$-helix/loop motif in the unliganded enzyme is colored purple, while the liganded form is colored yellow. Moiramide B is represented in ball and stick format, and the protein is shown in surface representation with two residues from the $\beta$-subunit noted (Phe230 and Gln249). 


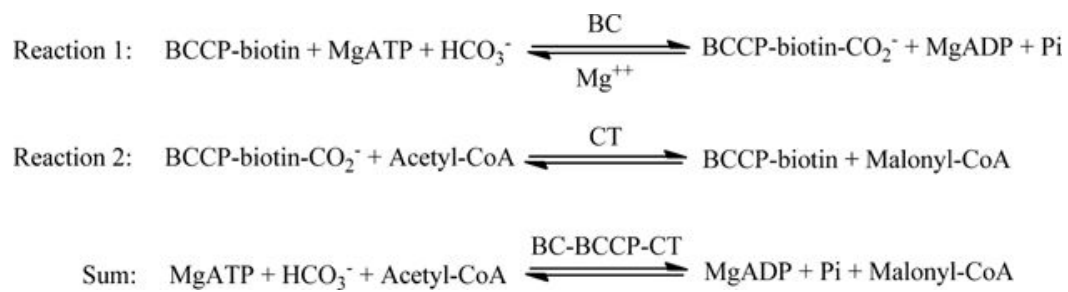

Scheme 1.

Reactions of Biotin Carboxylase (BC) and Carboxyltransferase (CT) Along with the Sum of the Entire Acetyl-CoA Carboxylase Reaction 


\section{Table 1}

\section{Data Collection and Refinement Statistics}

\begin{tabular}{|c|c|}
\hline \multicolumn{2}{|l|}{ Data Collection } \\
\hline wavelength $(\AA)$ & 0.97918 \\
\hline resolution $(\AA)$ & $40-2.6$ \\
\hline temperature $(\mathrm{K})$ & 100 \\
\hline space group & $C 2$ \\
\hline \multicolumn{2}{|l|}{ cell dimensions } \\
\hline$a(\AA)$ & 153.807 \\
\hline$b(\AA)$ & 49.445 \\
\hline$c(\AA)$ & 100.048 \\
\hline$\beta(\operatorname{deg})$ & 91.94 \\
\hline no. of complexes per asymmetric unit & 1 \\
\hline no. of unique reflections & 23238 \\
\hline$R_{\text {pim }}^{a, b}(\%)$ & $6.1(46.0)$ \\
\hline$R_{\mathrm{sym}}^{c}(\%)$ & $9.1(68.7)$ \\
\hline completeness $(\%)$ & $99.1(98.5)$ \\
\hline redundancies & $3.7(3.7)$ \\
\hline$I / \sigma(I)$ & $6.8(1.5)$ \\
\hline $\mathrm{CC}_{1 / 2}{ }^{d}$ & $0.995(0.819)$ \\
\hline \multicolumn{2}{|l|}{ Refinement } \\
\hline resolution range $(\AA)$ & $40-2.6$ \\
\hline no. of reflections used in refinement & 22099 \\
\hline$\sigma$ cutoff used in refinement & 0 \\
\hline$R, R_{\text {free }}(\%)^{e}$ & $22.95,27.59$ \\
\hline \multicolumn{2}{|l|}{ no. of refined atoms } \\
\hline protein & 4264 \\
\hline heterogeneous atoms & 53 \\
\hline water & 21 \\
\hline \multicolumn{2}{|l|}{ average $B$ factor $\left(\AA^{2}\right)$} \\
\hline protein & 66.9 \\
\hline moiramide & 61.8 \\
\hline water & 43.2 \\
\hline \multicolumn{2}{|l|}{ rmsd } \\
\hline bonds $(\AA)$ & 0.005 \\
\hline angles (deg) & 1.005 \\
\hline
\end{tabular}

aValues in parentheses are for the highest-resolution shell.

$b R_{\mathrm{pim}}=\left[\sum_{\mathrm{hkl}}(1 / n-1) \sum_{j=1}^{n}\left|I_{\mathrm{hkl}, j}-\left\langle I_{\mathrm{hkl}}\right\rangle\right| / \sum_{\mathrm{hkl}} \sum_{j} I_{\mathrm{hkl}, j}\right] \times 100$, where $\left\langle I_{h k l}\right\rangle$ is the average of the symmetry (or Friedel)-related observations of a unique reflection, $I_{i}$ is the intensity of the $i$ th observation, and $\left\langle I_{i}\right\rangle$ is the mean intensity of the reflection.

${ }^{c} R_{\mathrm{Sym}}=\Sigma\left|I_{\dot{\Gamma}}\left\langle I_{i}\right\rangle\right| \Sigma I_{j}$, where $I_{i}$ is the intensity of the $\dot{t}$ th observation and $\left\langle I_{i}\right\rangle$ is the mean intensity of the reflection. 
$d_{\text {Reported in ref } 19 .}$

${ }^{e} R=\Sigma\left\|F_{\mathrm{O}}|-| F_{\mathrm{C}}\right\| / \Sigma\left|F_{\mathrm{O}}\right|$, where $F_{\mathrm{O}}$ and $F_{\mathrm{C}}$ are the observed and calculated structure factors amplitudes, respectively. $R_{\text {free }}$ is calculated using $4.8 \%$ of the reflections omitted from the refinement. 